\title{
MJERE ZA SPREČAVANJE LIKVEFAKCIJE USLJED DINAMIČKOG OPTEREĆENJA
}

mr Bojana Grujić, dipl.građ.inž. ${ }^{1}$

Doc. dr Igor Jokanović, dipl.građ.inž. ${ }^{2}$

Dragana Zeljić, dipl.građ.inž. ${ }^{3}$

Žarko Grujić, dipl.građ.inž. ${ }^{4}$

UDK: 624.131 .54

DOI:10.14415/konferencijaGFS 2016.061

Rezime: Likvefakcija se pojavljuje kao jedan od sporednih efekata jakih zemljotresa. Može se definisati kao fenomen transformacije stabilnog $i$ čvrstog tla u stanje guste tečnosti. Likvefakcija se može desiti pod uticajem zemljotresa ili drugog dinamičkog opterećenja u slučaju visokog nivoa zasićenosti tla. Glavni faktori koji utiču na likvefakcioni potencijal tla su nizak indeks zbijenosti $i$ visok stepen zasićenja vodom. Opasnost leži u fatalnom preturanju objekata što izaziva dalja oštećenja $i$ diferencijalnom slijeganju konstrukcija koja nastaju usljed naglog gubitka čvrstoće. $U$ radu je prikazana analiza potencijala za pojavu likvefakcije i predstavljene različite mjere zaštite protiv likvefakcije.

Ključne reči: likvefakcija, dinamičko opterećenje, zasićenje tla, mjere zaštite

\section{UVOD}

Likvefakcija je fenomen koji se javlja u nekonsolidovanom, vodom zasićenom tlu koje je pogođeno seizmičkim talasima uzrokovanih vibracijama Zemlje. Iako je zemljotres jedan od najpoznatijih uzroka likvefakcije, postoje i drugi načini da se izazove ova pojava kao što su miniranje ili slična dinamička opterećenja koja doprinose promjeni strukture zrna okolnog tla. Pješčano, muljevito i šljunkovito tlo su najviše podložni procesu likvefakcije. S obzirom na to da se zrnasti materijali sastoje od mješavine zemljanog materijala i pornih šupljina, u slučaju pojave zemljotresnog šoka porni prostor biva ispunjen vodom i doživljava kolaps, što smanjuje ukupnu zapreminu tla. Ovaj proces dovodi do povećanja pritiska vode između pojedinih zrna tla tako da se ona mogu slobodno kretati u vodenoj matrici. To značajno smanjuje otpornost tla i doprinosi

\footnotetext{
${ }^{1}$ Univerzitet u Banjoj Luci, Arhitektonsko-građevinsko-geodetski fakultet, Bulevar vojvode Stepe Stepanovića 77/3, Banja Luka, Republika Srpska, Bosna i Hercegovina, e-mail: bgrujic@agfbl.org

${ }^{2}$ Univerzitet u Novom Sadu, Građevinski fakultet, Kozaračka 2a, Subotica, Republika Srbija,

e-mail: jokanovici@gf.uns.ac.rs

${ }^{3}$ Univerzitet u Banjoj Luci, Arhitektonsko-građevinsko-geodetski fakultet, Bulevar vojvode Stepe Stepanovića 77/3, Banja Luka, Republika Srpska, Bosna i Hercegovina, e-mail: dzeljic@agfbl.org

${ }^{4}$ Univerzitet u Banjoj Luci, Arhitektonsko-građevinsko-geodetski fakultet, Bulevar vojvode Stepe Stepanovića 77/3, Banja Luka, Republika Srpska, Bosna i Hercegovina, e-mail: zgrujic@agfbl.org
} 
Contemporary achievements in civil engineering 22. April 2016. Subotica, SERBIA

činjenici da tlo poprima karakteristike tečnosti. Konstrukcije koje su izgrađene na ili u tlu koje je podložno likvefakciji, mogu pretrpjeti značajna oštećenja usljed naglog gubitka ,podrške“ od strane tla koje je zahvaćeno procesom likvefakcije.

\section{OPIS I ANALIZA POJAVE LIKVEFAKCIJE}

Likvefakcija se definiše kao transformacija nekoherentnog tla iz čvrstog u tekuće stanje, i posljedica je porasta pornog pritiska i smanjenja efektivnih naprezanja. Povećanje pornog pritiska nastaje kao posljedica cikličnih, smičućih deformacija u tlu, čije se čestice nastoje zbiti i zauzeti stabilan položaj (Slika 1).

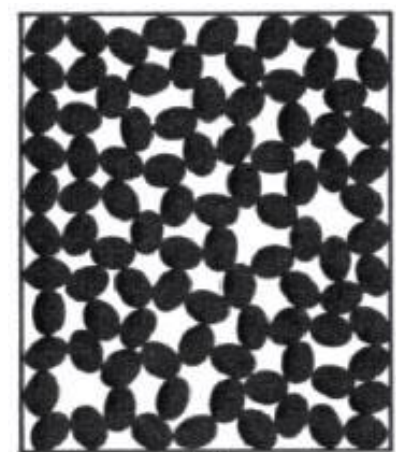

(a)

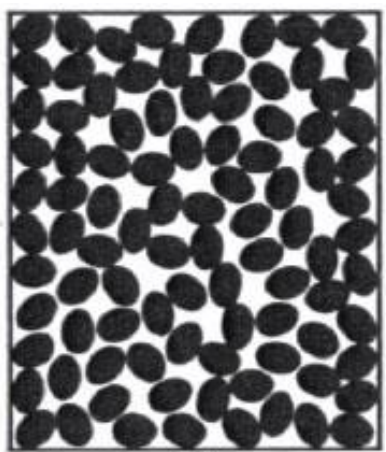

(b)

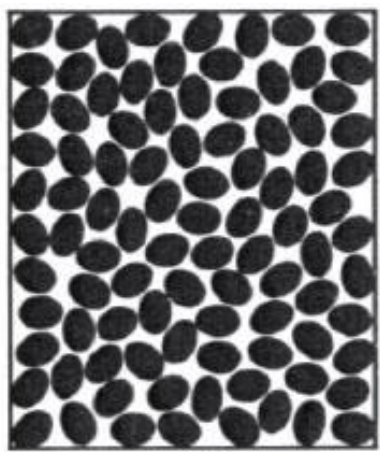

(c)

Slika 1. Model likvefakcije pijeska [1]

(a) stanje mirovanja-čestice se međusobno dodiruju; (b) početak zemljotresa-neka zrna su izdvojena, djelimično likvefirani materijal; (c) duže trajanje procesa, nijedna čestica ne dodiruje drugu, potpuno likvefiran, tekući pijesak

U slučaju postojanja mogućnosti dreniranja tla, zapremina tla će se smanjiti i neće doći do likvefakcije. Usljed djelovanja zemljotresa kao cikličnog opterećenja, pri čemu je spriječeno dreniranje tla $u$ oba pravca, promjena zapremine se ne može ostvariti. U takvim okolnostima dolazi do prenošenja opterećenja sa čestica na pornu vodu, pri čemu se povećava porni pritisak, a istovremeno smanjuje nosivost tla. Karakteristične pojave koje mogu nastati usljed likvefakcije su prikazane u Tabeli 1.

Tabela 1. Klasifikacija posljedica likvefakcije [2]

\begin{tabular}{|l|l|l|}
\hline \multicolumn{1}{|c|}{ stanje naprezanja u tlu } & \multicolumn{1}{|c|}{ ponašanje tla } & karakteristična pojava na terenu \\
\hline nema smičućih naprezanja & - smanjenje zapremine & - slijeganje tla \\
\hline povećanje pornog pritiska & $\begin{array}{l}\text { muljni vulkani i prskanje iz } \\
\text { površinskih pukotina }\end{array}$ \\
\hline $\begin{array}{l}\text { smičuća naprezanja veća od } \\
\text { rezidualne čvrstoće }\end{array}$ & - gubitak stabilnosti & - tečenje tla \\
& - likvefakcija & $\begin{array}{l}\text { tonjenje zgrada } \\
\text { plutanje lakših objekata }\end{array}$ \\
\hline
\end{tabular}




\begin{tabular}{|c|c|c|}
\hline $\begin{array}{l}\text { smičuća naprezanja manja od } \\
\text { rezidualne čvrstoće }\end{array}$ & $\begin{array}{l}\text { - } \text { ograničena smičuća } \\
\text { distorzija } \\
\text { - } \text { masa tla ostaje stabilna }\end{array}$ & $\begin{array}{l}\text { - } \text { klizanje kosina } \\
\text { - diferencijalno slijeganje zgrada } \\
\text { - bočno širenje }\end{array}$ \\
\hline
\end{tabular}

Da bi se donio zaključak o mogućnosti pojave likvefakcije na nekoj lokaciji pri jačem zemljotresu potrebno je predmetnu lokaciju posmatrati uzimajući u obzir višestruke aspekte, pri čemu je najvažniji geotehnički izvještaj koji bi trebalo da pruži sljedeće podatke (bez obzira da li se radi o konkretnom ispitivanju rizika od pojave likvefakcije ili je ispitivanje rađeno za potrebe nekog većeg projekta):

- granulometrijska kriva (prisustvo materijala koji je podložan pojavi likvefakcije);

- stanje zbijenosti materijala (jedan od najvažnijih parametara koji dobrim dijelom zavisi od starosti materijala);

- stepen zasićenosti materijala;

- strateški položaj lokacije;

- zona seizmičke aktivnosti za predmetnu lokaciju;

- pojava likvefakcije u prošlosti na razmatranoj lokaciji.

Vjerovatnoća pojave likvefakcije najpouzdanije se određuje modifikovanim programom PROLIQ2 [3] koji koristi metode Seed-a i Idriss-a razvijene poslije katastrofalnih zemljotresnih pojava na Aljasci i Niigati 1964. godine (Slika 1).
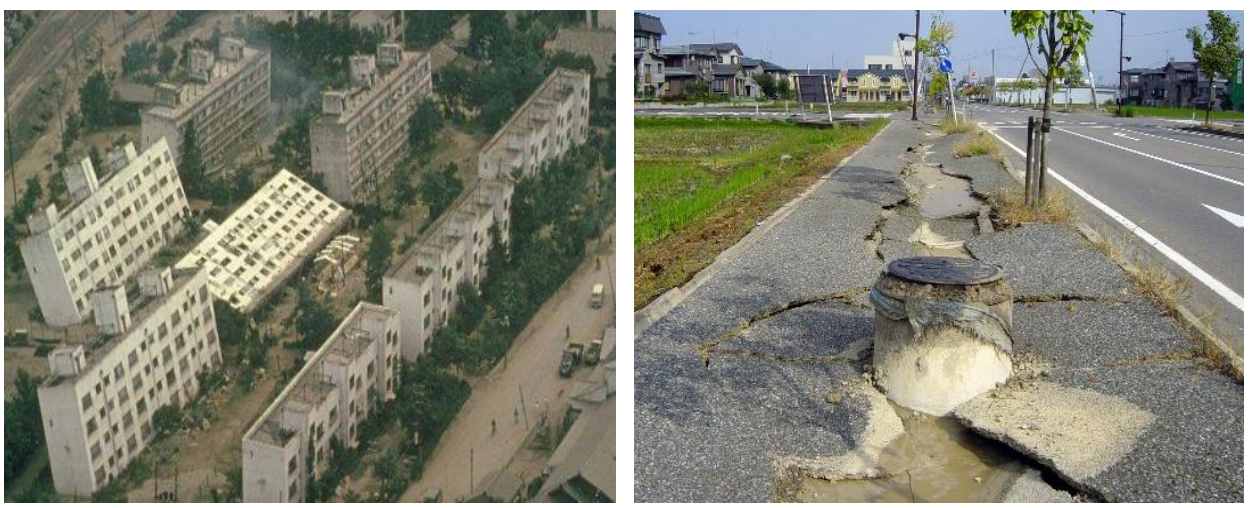

Slika 1. Posljedice pojave likvefakcije nakon zemljotresa (Niigata Chuetsu zemljotres, Japan) [izvor: Internet]

Tabela 2. prikazuje osnovne parametre koji su potrebni za određivanje vjerovatnoće pojave likvefakcije programom PROLIQ2, kao i primjer proračuna.

Pored mogućnosti određivanja pojave likvefakcije programom PROLIQ2, ista se može odrediti i koristeći ispitivanja standardnim penetracionim opitom (SPT) što je i najčešće korišćen način utvrđivanja podložnosti tla likvefakciji u svijetu.

Kada se koristi dinamički pristup procjeni pojave likvefakcije, otpornost tla prema likvefakciji se izražava koeficijentom sigurnosti koji je dat sljedećim izrazom [4]:

$$
\mathrm{FS}_{\mathrm{L}}=\frac{\mathrm{CRR}_{7_{2} 5}}{\mathrm{CSR}} \times \mathrm{MSF} \cdot \mathrm{K}_{\mathrm{a}} \cdot \mathrm{K}_{\sigma}
$$


Contemporary achievements in civil engineering 22. April 2016. Subotica, SERBIA

gdje je:

- $\mathrm{CRR}_{7,5}$ odnos cikličke otpornosti prema likvefakciji za zemljotres magnitude 7,5;

- CSR odnos cikličkih naprezanja koji su prouzrokovani zemljotresom;

- MSF faktor skaliranja magnitude zemljotresa (Slika 2);

- $\mathrm{K}_{\alpha} \quad$ koeficijent korekcije za statičko tangencijalno naprezanje (ako postoji) (Slika 3a);

- $\mathrm{K}_{\sigma} \quad$ koeficijent korekcije pritiska nadsloja (nasipa ili konstrukcije) (Slika 3b).

Tabela 2. Primjer proračuna vjerovatnoće pojave likvefakcije [1, 3, 5]

\begin{tabular}{|c|c|c|c|c|c|c|c|c|c|c|c|}
\hline \multicolumn{4}{|c|}{ B-30 (27) } & \multicolumn{4}{|c|}{ B-31 (28) } & \multirow{2}{*}{\multicolumn{2}{|c|}{ 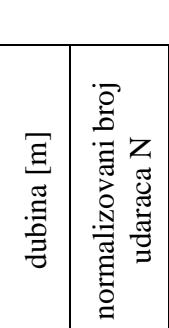 }} & \multirow[b]{2}{*}{ 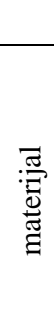 } & \multirow[b]{2}{*}{ 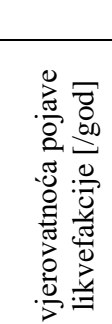 } \\
\hline 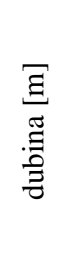 & 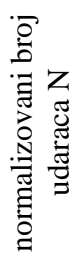 & 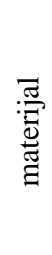 & 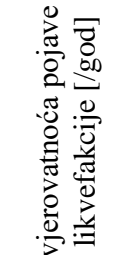 & 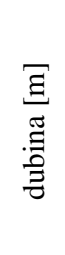 & 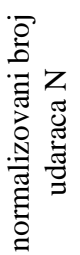 & 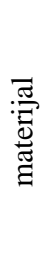 & 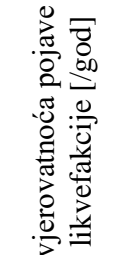 & & & & \\
\hline 2,0 & 14,4 & $S$ & 0,00797 & 2,0 & 5,5 & $\mathrm{~N}_{\mathrm{L}}$ & 0,00000 & 1,0 & 6,0 & $\mathrm{~N}_{\mathrm{L}}$ & 0,00000 \\
\hline 5,0 & 6,3 & $\mathrm{~S}$ & 0,09117 & 4,0 & 6,4 & $\mathrm{~N}_{\mathrm{L}}$ & 0,00000 & 3,0 & 6,0 & $\mathrm{~S}$ & 0,08551 \\
\hline 8,0 & 14,9 & $\mathrm{~N}_{\mathrm{L}}$ & 0,00000 & 5,0 & 6,0 & $\mathrm{~S}$ & 0,08849 & 5,0 & 14,8 & $\mathrm{~N}_{\mathrm{L}}$ & 0,00000 \\
\hline 11,0 & 13,5 & $\mathrm{~N}_{\mathrm{L}}$ & 0,00000 & 8,0 & 13,3 & $\mathrm{~N}_{\mathrm{L}}$ & 0,00000 & 7,0 & 14,5 & $\mathrm{~N}_{\mathrm{L}}$ & 0,00000 \\
\hline 18,0 & 10,2 & $\mathrm{~N}_{\mathrm{L}}$ & 0,00000 & 11,0 & 12,8 & $\mathrm{~N}_{\mathrm{L}}$ & 0,00000 & 9,0 & 13,4 & $\mathrm{~N}_{\mathrm{L}}$ & 0,00000 \\
\hline 20,0 & 3,9 & $S$ & 0,29788 & 17,0 & 10,0 & $\mathrm{~N}_{\mathrm{L}}$ & 0,00000 & 12,0 & 12,9 & $\mathrm{~N}_{\mathrm{L}}$ & 0,00000 \\
\hline & & & & 20,0 & 9,8 & $\mathrm{~N}_{\mathrm{L}}$ & 0,00000 & & & & \\
\hline & & & & 23,0 & 9,0 & $\mathrm{~N}_{\mathrm{L}}$ & 0,00000 & & & & \\
\hline
\end{tabular}

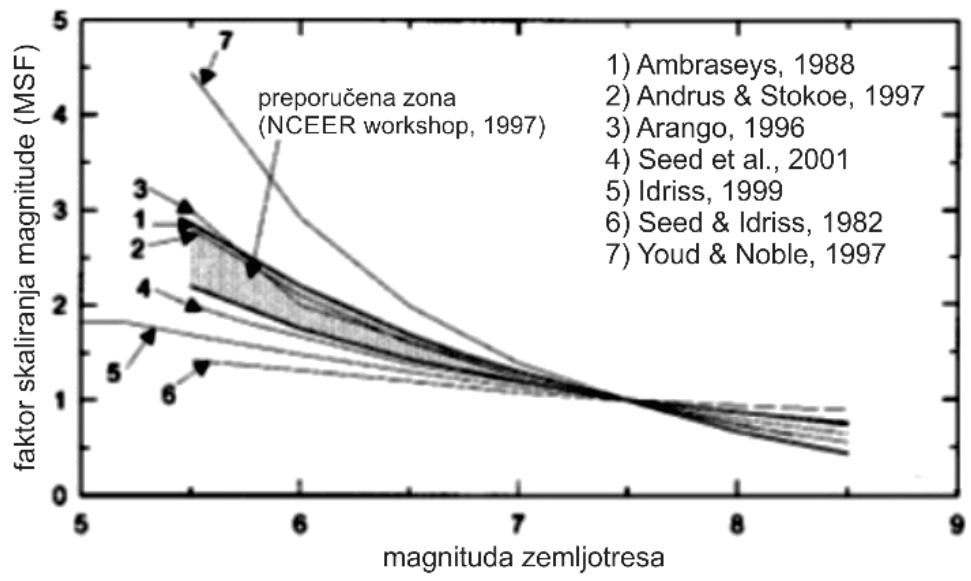

Slika 2. Faktor skaliranja magnitude zemljotresa [6] 


\section{MJERE ZAŠTITE OBJEKATA U SLUČAJU POJAVE LIKVEFAKCIJE}

Sprečavanje pojave likvefakcije može se odvijati kroz nekoliko usmjerenih akcija, i to:

- izbjegavanje gradnje objekata na tlu koje je podložno procesu likvefakcije;

- temeljenje konstrukcija prilagođeno tlu u kome je moguća pojava likvefakcije (vrsta, otpornost, krutost temeljne konstrukcije);

- mehaničko i hemijsko poboljšanje tla koje je podložno likvefakciji prije izgradnje objekata.

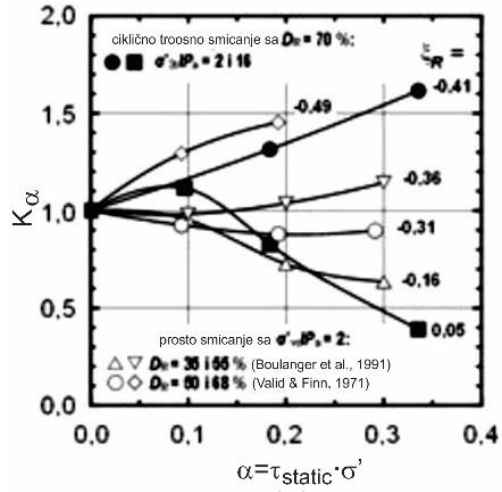

(a)

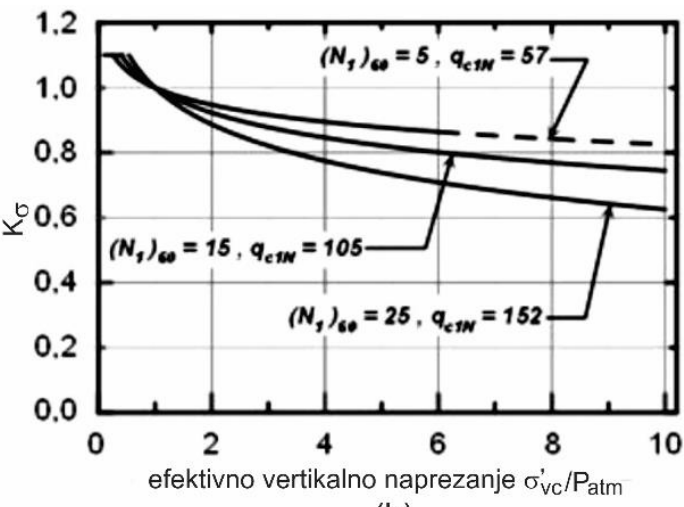

(b)

Slika 3. Koeficijenti korekcije za proračun otpornosti prema likvefakciji [7] (a) koeficijent korekcije za statičko tangencijalno naprezanje $K_{\alpha}$; (b) koeficijent korekcije pritiska nadsloja $K_{\sigma}$

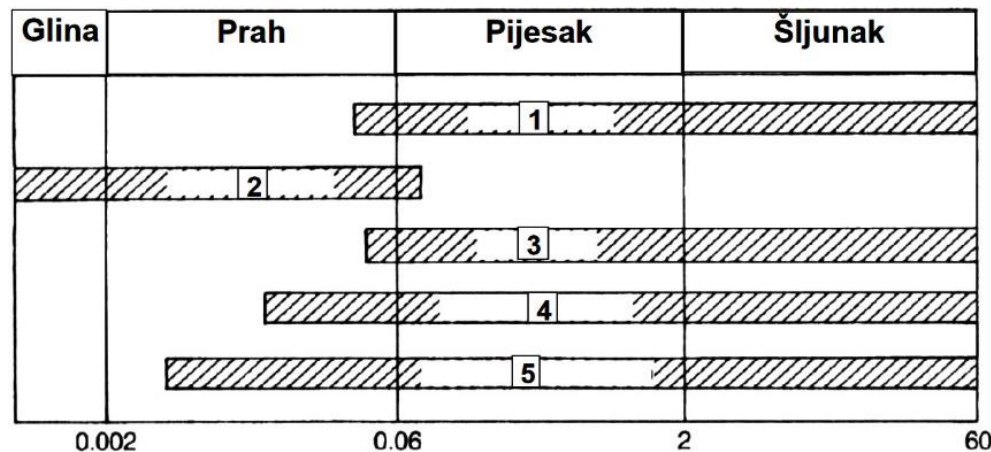

Slika 4. Metode dubokog zbijanja u različitim vrstama tla [5]

(1) vibraciona flotacija, (2) šljunčani ili kameni stubovi, (3) eksploziv,

(4) šljunčani šipovi, (5) dinamičko zbijanje 
Contemporary achievements in civil engineering 22. April 2016. Subotica, SERBIA

Obavljanje detaljnih istražnih radova i priprema geotehničkog elaborata doprinosi izboru i vrsti pristupa izgradnji na tlu koje je podložno likvefakciji, ukoliko se takvo tlo ne može izbjeći kao građevinsko zemljište.

Konstrukcije koje posjeduju dovoljnu žilavost mogu da prihvate velike deformacije prije samog sloma, a tome u prilog ide plitko temeljenje i oblikovanje temeljne konstrukcije kao temeljne ploče ili temeljnog roštilja, na koji način se ravnomjerno prihvata slijeganje.

Najrasprostranjeniji način suprotstavljanja pojavi likvefakcije su svakako različite metode poboljšanja tla (Slika 4).

Zbijanje i zamjena tla podložnog likvefakciji podrazumijeva zamjenu lošeg tla (uz korištenje eksploziva) odgovarajućom količinom šljunka. Na ovaj način postiže se poboljšanje oblika granulometrijske krive, a samim tim tlo je manje podložno procesu likvefakcije. Pored ovog načina mehaničke stabilizacije, moguća je i primjena hemijske stabilizacije krečom i cementom. Svakako, trebalo bi posmatrati i ekonomsku stranu primjene ove metode $\mathrm{i}$ granicu njene isplativosti.

Primjena drenaže ima za cilj odvođenje vode iz okolnog tla, te se na taj način smanjuje mogućnost pojave likvefakcije. Drenovi su uglavnom šljunčani sa većom propusnom moći od iste za okolno tlo.

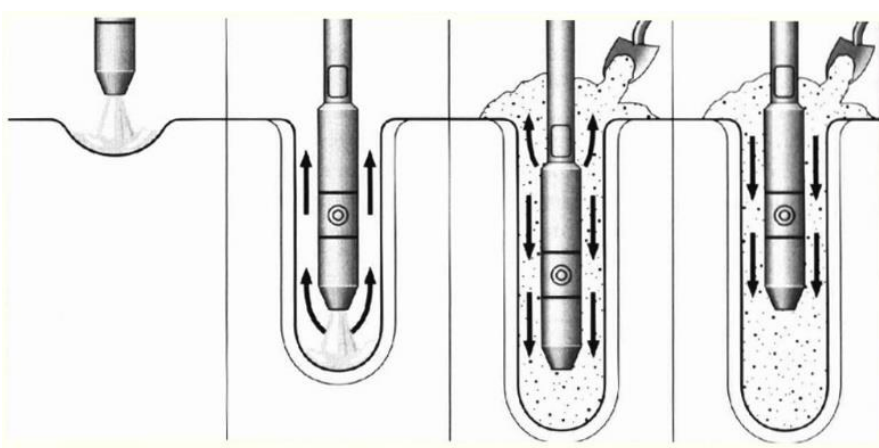

Slika 5. Princip vibroflotacije [5]

Šljunčani šipovi predstavljaju jednu od najboljih metoda za sprečavanje pojave likvefakcije jer je uloga ovih šipova dvostruka. S jedne strane utiču na poboljšanje zbijenosti materijala u koji se pobijaju, a s druge strane, pošto se izvode uz vibriranje, utiču na smanjenje likvefakcijskog potencijala što je prvi preduslov smanjenja ili eliminisanja ove negativne pojave u tlu. Šljunčani šipovi, kao što je već napomenuto, imaju drenirajuća svojstva i kao takvi apsolutno mijenjaju sliku pornih pritisaka i doprinose povećanju efektivnih naprezanja, što je i krajnji cilj sprečavanja likvefakcije.

Vibroflotacija (Slika 5) predstavlja postupak poboljšanja relativne zbijenosti materijala, a time $i$ fizičko-mehaničkih karakteristika tla s tim što postoji određeno ograničenje $u$ pogledu pogodnosti primjene ovog procesa u zavisnosti od vrste tla (Slika 6). U krupnozrnom tlu, proces se obavlja vibriranjem, dok se u sitnoznom (koherentnom) tlu postupak provodi izvođenjem vertikalnih šljunčanih ili pješčanih drenova ili šipova, te se na taj način postiže bolja zbijenost, ali i procjedjivanje okolnog materijala. Vibroflotacija 
se primjenjuje za poboljšanje karakteristika geotehničkih građevina (nasipa) koji se koriste za zaštitu od poplava.

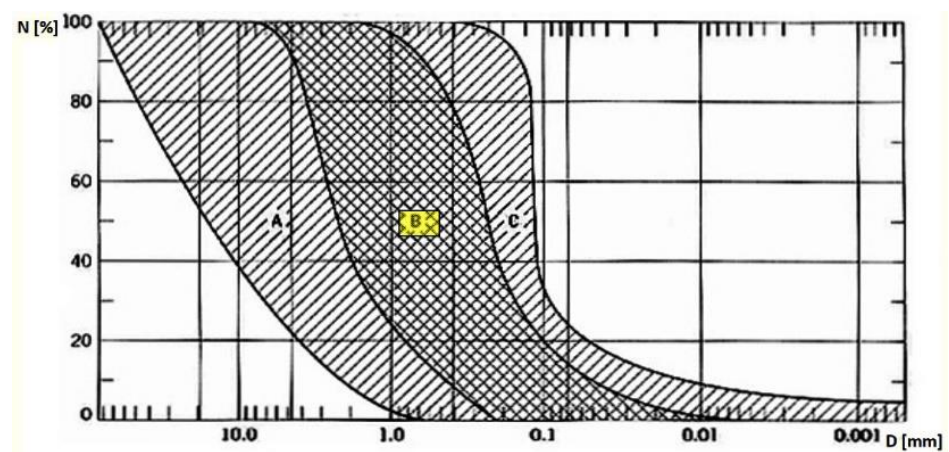

Slika 6. Tla koja su pogodna za vibroflotaciju

A-krupne čestice tla, mogućnost napredovanja mala; B-povoljna zona za vibroflotaciju; C-teško je postići dobre efekte zbijenosti materijala [5]

\section{ZAKLJUČAK}

Imajući u vidu da je izgradnja različitih vrsta objekata visokogradnje i niskogradnje praćena stalnim naporom graditelja da savladaju različita naponska stanja u tlu, pojava likvefakcije pod dejstvom zemljotresa ili nekog drugog dinamičkog opterećenja predstavlja veliki izazov, posebno u urbanizovanim sredinama. Današnja tehnološka dostignuća omogućavaju bolji pristup i razvoj novih metoda za sprečavanje pojave likvefakcije, s obzirom na mjesto i način pojavljivanja opisanog stanja u tlu.

Međutim, nepovoljna okolnost je da sistemsko zoniranje prema potencijalu likvefakcije na teritorijama republika bivše Jugoslavije nikada nije provedeno, kako ukupno, tako ni na nivou manjih teritorijalnih jedinica (regioni, opštine i sl). U zavisnosti od pojedinačnih inicijativa ozbiljnih stručnjaka geotehničke struke, ova istraživanja su u određenoj meri rađena za pojedinačne objekte.

Obzirom na seizmičnost teritorije bivše Jugoslavije, postojanje likvefabilnih materijala (uniformno graduirani pijesak, pijesak s primjesama prašine i krupnozrna prašina), kao i pojave likvefakcije u prošlosti, pri projektovanju objekata je neophodno uzeti u obzir i potencijal likvefakcije, te primjeniti odgovarajuća preventivna rješenja za sprečavanje iste.

\section{LITERATURA}

[1] Veinović, Ž., Domitrović, D., Lovrić, T., Pojava likvefakcije na području Zagreba u prošlosti i procjena mogućnosti ponovne pojave tijekom jačeg potresa, Rudarskogeološko-naftni zbornik, Vol. 19, 2007, s. 111-120. 
Contemporary achievements in civil engineering 22. April 2016. Subotica, SERBIA

[2] Rauch, A.F., EPOLLS: An Empirical Method for Predicting Surface Displacements Due to Liquefaction-Induced Lateral Spreading in Earthquakes, Ph.D. dissertation, Virginia Tech, Blacksburg, 1997

[3] Atkinson, G.M., Finn, L., Charlwood, R.G., PROLIQ2 - A Computer Program for Estimating the Probability of Seismic Liquefaction Including Both Areal \& Fault Sources, UBC Canada, Vancouver, 1986

[4] Youd, T.L., Idriss, I.M., Liquefaction resistance of soils: Summary report from the 1996 NCEER and 1998 NCEER/NSF workshops on evaluation of liquefaction resistance of soils, Journal of Geotechnical and Geoenvironmental Engineering, vol. 127, No. 4, 2001, p. 817-833.

[5] Veinović, Ž., Ocjena mogućnosti pojave likvefakcije i definiranje osnove za likvefakcijsko zoniranje Republike Hrvatske, doktorska disertacija, Rudarskogeološko-naftni fakultet, Sveučilište u Zagrebu, Zagreb, 2007

[6] Kramer, S., Asl, B.A., Sideras, S., Effects of Long Duration Motions on Ground Failure, 2013 EERI Annual Meeting: Building Resilient Communities Through Policy and Mitigation, Seattle, 2013 (dostupno na: http://2013am.eerievents.org/conference-presentations)

[7] Boulanger, R.W., Ziotopoulou, K., PM4Sand (Version 2): A Sand Plasticity Model for Earthquake Engineering Applications, Report No. UCD/CGM-12/01, Center for Geotechnical Modeling, Department of Civil \& Environmental Engineering, College of Engineering, University of California at Davis, 2012

\section{MEASURES FOR PREVENTION OF LIQUEFACTION DUE TO DYNAMIC LOADING}

Summary: Liquefaction appears as one of the side effects of strong earthquakes. It can be defined as a phenomenon of transformation of stable and solid ground in the state of a thick liquid. Liquefaction may occur under the influence of an earthquake or other dynamic loads in case of high soil saturation. Main factors influencing the liquefaction potential of the soil are low index of compactness and high degree of water saturation. The danger lies in fatal tumbling of structures causing further damage and differential settlements of structures that occur due to a sudden loss of strength. Paper presents analysis of liquefaction potential and various protective measures against liquefaction.

Keywords: liquefaction, dynamic loading, soil saturation, protective measures 